\title{
Predator mediated coexistence of hybrid and parental Daphnia taxa
}

\author{
Piet Spaak ${ }^{1,2 *}$ and Maarten Boersma ${ }^{3,2}$
}

With 6 figures and 2 tables

\begin{abstract}
We used Daphnia as a model to study the effect of predators on clonal and taxon coexistence within the same habitat. Different Daphnia species and their hybrids coexist in many lakes worldwide. We studied the potential influence of planktivorous fish on the maintenance of these species assemblages using 20 Daphnia clones, belonging to five hybrid and parental taxa of the Daphnia galeata-hyalina-cucullata complex originating from the Plußsee (Northern Germany). With these clones, two competition experiments were conducted in two large-scale indoor mesocosms, the Plankton Towers in Plön, Germany. We varied the presence of fish and kairomones. Using allozyme electrophoresis we observed Diel Vertical Migration (DVM) of individual clones. Without fish, two clones belonging to the largest taxa (D. galeata and $D$. galeata $\times$ hyalina) became numerically dominant after three weeks. The mere presence of fish kairomones led to a significant decrease in the niche overlap between the five taxa. With fish present in the towers relative densities of smaller D. cucullata $\times$ galeata clones were highest. We observed that under different predation intensities different taxa showed the highest instantaneous rate of increase. Without fish and fish kairomones this rate was the highest for $D$. galeata, when fish kairomones were present $D$. galeata $\times$ hyalina had the highest relative $r$. With increasing fish predation $D$. cucullata and D. cucullata $\times$ galeata had the highest relative $r$, respectively, showing that changing predation pressure facilitates the co-occurrence of taxa in this species complex.
\end{abstract}

Key words: fish predation, inducible defence, interspecific hybridization, competition, hybrid superiority.

\footnotetext{
1 Authors' addresses: Eawag, Swiss Federal Institute of Aquatic Science and Technology, Postfach 611, 8600 Dübendorf, Switzerland.

2 Max-Planck-Institut für Limnologie, Postfach 165, 24302 Plön, Germany.

3 Alfred-Wegener-Institut für Polar- und Meeresforschung, Biologische Anstalt Helgoland, Postfach 180, 27483 Helgoland, Germany.

* Corresponding author; E-mail: spaak@eawag.ch
} 


\section{Introduction}

The question why different species hybridize in nature and why these hybrids persist in populations has been a long-standing topic among ecologists and evolutionary biologists (e.g. DARWIN 1859, ANDERSON 1953, ArNold 1997). The biological species concept (MAYR 1942) and the phylogenetic species concept (CRACRAFT 1989) denied the existence of hybrid forms, simply by defining a species as a group of organisms that interbreed. From this perspective, hybridization was considered insignificant because individual species are reproductively isolated (MAYR 1963) or because new species cannot be polyphyletic in origin (HENNIG 1966, CRACRAFT 1989). We, however, prefer the definition of hybridization from ARNOLD (1997) which does not depend on a specific species concept. It defines natural hybridization as the process in which successful mating occurs in nature between individuals from two or more populations, which are distinguishable on the basis of one or more heritable characters.

Compared to other evolutionary processes such as natural selection and drift, hybridization is a very fast process in which individuals with a completely new combination of genes are formed within one generation. The evolutionary significance of hybridization might be either in transferring genes from one taxon to another through introgression (ANDERSON \& STEBbins 1954, LEHMAN et al. 1991, GRANT 1993), or as a first step in the formation of a new species. In fact, many plant (e.g. Stace 1987, Whitham et al. 1991) and animal (BULLINI 1985, SEEHAUSEN 2004) species are known to have a hybrid origin.

Although hybrids are widely distributed in nature, hybridization events seem to be relatively rare. Two factors determine the incidence of hybrids between taxa, first, the frequency of their production, and secondly the ecological success (e.g. fitness) of the hybrids, once they are produced. The production of hybrids occurs in hybrid zones, regions where two species co-occur and mate. Two groups of models address the maintenance of these zones. The tensions zone models (BARTON \& HEWITT 1985), which are based on a lower fitness of the hybrids compared to the parental forms, and the bounded hybrid superiority models (Moore 1977, Moore \& Koenig 1986), which are based on a higher fitness of the hybrids in specific habitats. Although most hybrid work is based on the tension zone principle (for review see ARNOLD 1997), several recent studies have shown that in specific cases, hybrid taxa can be as fit as their parental taxa (SCRIBNER 1993, BERT \& ARNOLd 1995, SPAAK \& HoEKSTRA 1995, Grant \& Grant 2002).

In aquatic habitats, especially lakes, the concept of hybrid zones is difficult to apply, because the spatial separation between taxa is limited and in open water no clear zones exist were fitness differences can be expressed. There- 
fore, in these habitats research has focused mainly on the comparison of different lakes and the co-occurrence of hybrids and parental species over a range of lakes. Species of the waterflea Daphnia (Crustacea, Anomopoda) have been studied extensively in this context (SCHWEnK \& SpaAK 1995). Within the $D$. galeata complex (D. galeata SARS, D. cucullata SARS and D. hyalina LEYDIG), hybrids are very common and are found in many European lakes. In these lakes, they are often the dominant taxa and co-occur with one or both parental species (for review see: ScHWENK \& SPAAK 1997). Hybridization has also been described for other genera of cladocerans, including Bosmina (LIEDER 1987), Simocephalus (Hann \& Hebert 1982), and Pleuroxus (Shan \& Frey 1983). Most Daphnia species are cyclic parthenogens, and reproduce sexually only when growing conditions deteriorate. Their sexual eggs are diapausing stages, which mostly sink to the bottom of the lake, but a certain fraction floats and can be transported by waterfowl (CREASE et al. 1997) to other habitats. Although hybrids are able to reproduce sexually, and evidence for introgression exists (SPAAK 1996, ScHWENK \& SPAAK 1997) it is still unclear how successful sexual offspring of these hybrids really are, especially since the parental taxa are still very distinct, and do not consist of a hybrid swarm with all possibilities of intermediate phenotypes (SCHWENK \& SPAAK 1997). The fact that some Daphnia lineages of hybrid origin produce diapausing eggs only parthenogenetically, although an indication of limited hybrid sexual success (WEIDER et al. 1996), may in fact represent a first step in the speciation process. However, hybrid daphnids produce subitaneous eggs just as well as their parental species, enabling them to establish high population densities within a growing season (e.g. SPAAK \& HoEkstra 1997). Moreover, in many larger and deeper lakes, a fraction of the hybrid population is also known to survive the winter as parthenogenetic individuals (WEIDER \& STICH 1992, SPAAK 1996). The main explanation for the high abundance of Daphnia hybrids in many lakes is, therefore, most likely not the frequent production of hybrids but their competitive abilities. As a result of the blend of parental traits, hybrids may possess a competitive advantage, in comparison with parental species, under some environmental conditions (BOERSMA \& VIJVERBERG 1994, SPAAK \& HoEKsTRA 1995, 1997). One of the most important factors mediating coexistence of several Daphnia taxa is probably size selective predation by fish (SPAAK \& Hoekstra 1995, 1997).

Ever since the development of the Size Efficiency Hypothesis (BrooKs \& DoDson 1965), it has been generally accepted that larger planktonic species are better competitors (VANNI 1986, GLIWICZ \& LAMPERT 1990), dominating communities when vertebrate predators are absent. However, the larger species are more vulnerable to fish predation. Fish not only directly influence Daphnia populations through predation, they also produce chemicals, kairomones, which induce changes in life-history traits, behaviour, and morphology 
of their prey in such a way that the predation risk decreases (e. g. LAss \& SPAAK 2003). Hence, when exposed to these kairomones, larger taxa should react more than smaller ones, as they face the highest risk from vertebrate predators. Typical reactions include remaining smaller (SPAAK et al. 2000, PIJANOWSKA et al. 2006) or migrating into the deeper layers of a lake, where predation risks are lower (DE MEester et al. 1995, ViJVERBERG et al. 2006). The implication of this is that the mere presence of fish influences different taxa differently (see also BoERsma et al. 1998), thus possibly changing the competitive abilities of these prey taxa, and as such mediating coexistence of different prey taxa.

In this study, we set out to test the hypothesis that the presence of predators (i.e. by inducing anti-predator defences) can slow-down the process of competitive exclusion among parentals and hybrids, when compared to predatorfree conditions. This could be realized either by attenuating differences in competitive ability among taxa or by decreasing niche overlap among taxa. We focused on one system, Lake Plußsee in Northern Germany (OvERBECK \& Chróst 1994), where three species of the D. galeata complex co-occur with all three possible hybrids. The lake has a maximal depth of $29.2 \mathrm{~m}$, which allows the daphnids to escape from fish predation during the day by Diel Vertical Migration (DVM, STICH \& LAMPERT 1981). In the Plöner Plankton Towers (LAMPERT \& LOOSE 1992), we mimicked the conditions of the lake, changing food and predation levels only. In this system, we studied the composition of the Daphnia population consisting of 20 clones from five parental and hybrid taxa. These clones had been previously investigated in life-history experiments (SPAAK et al. 2000), which demonstrated that there is a significant positive correlation between size at maturity (SAM) and intrinsic rate of increase, $r$. Based on these data, we expect the larger taxa D. galeata and D. galeata $\times$ hyalina to have the highest $r$, and hence dominate the Daphnia population numerically under conditions without fish kairomones. The differences with the other taxa are expected to become smaller when kairomones are added to the water, because of different migration strategies and changes in life histories. In the actual presence of planktivorous fish, larger taxa are expected to disappear completely because of size-selective predation. Verification of these expectations would confirm our hypothesis that fish enhance the coexistence of hybrid and parental taxa.

\section{Material and methods}

\section{Field site and sampling}

The Plußsee is a small (14.3 ha) funnel-shaped forest lake (Overbeck \& Chróst 1994) in Northern Germany. It is stratified for a large part of the year with an anoxic zone 
that starts between 6 and $8 \mathrm{~m}$ depth. Mean depth of this eutrophic lake is $9.4 \mathrm{~m}$, and the maximum depth is $29.2 \mathrm{~m}$. The fish fauna of the Plußsee consists of 13 species; roach (Rutilus rutilus) and perch (Perca fluviatilis) comprise about $70 \%$ of the standing stock (Krambeck et al. 1994). The Daphnia community consists of D. galeata, D. cucullata, D. hyalina, and the hybrids $D$. cucullata $\times$ galeata, D. cucullata $\times$ hyalina and D. galeata $\times$ hyalina $($ Wolf $\&$ MorT 1986, SPAAK 1995).

From September 1995 until May 1996 and during 1997, we sampled the lake regularly to determine the taxon composition and the genetic diversity of Daphnia. On 30 May 1996 and 11 June 1996 around noon and midnight, we collected plankton at $1 \mathrm{~m}$ depth intervals using a $23 \mathrm{~L}$ Schindler water sampler. If present, 60 adult individual Daphnia from each sample were randomly selected. Body length, defined as the distance between the top of the eye and the base of the tailspine was measured, and individual daphnids were frozen at $-80{ }^{\circ} \mathrm{C}$ in microtiter plates for later electrophoretic analysis. The rest of each sample was preserved in $4 \%$ formaldehyde and counted later to determine densities.

To collect our experimental animals, samples were taken by vertical hauls on 5 and 20 September 1995, and were transported to the laboratory. Adult females with parthenogenetic eggs were randomly selected from the lake sample and reared individually in the laboratory. All animals were assayed at four allozyme loci. The enzymes and their EC (Enzyme Commission) codes were: aldehyde oxidase (Ao, EC 1.2.3.1), aspartate aminotransferase (Aat, EC 2.6.1.1), phosphoglucomutase (Pgm, EC 5.4.2.2) and phosphoglucose isomerase (Pgi, EC 5.3.1.9). All electrophoresis was carried out on Titan III $^{\odot}$ cellulose acetate plates (Helena Scientific, Beaumont, TX, USA) using standard methods (HEBERT \& BEATON 1989). In this way, we obtained 170 isolates with known genotypes. Aat was used to identify the taxa (Wolf \& MorT 1986). For each taxon, we chose, if possible, four multi-locus genotypes randomly from the list of genotypes, and from each of those genotypes we used one clone in our experiments. At the time of sampling we found no D. hyalina and no variation in the hybrid D. cucullata $\times$ hyalina in Plußsee. For the hybrid D. galeata $\times$ hyalina very limited variation was found, therefore three out of the four clones we used had the same multi-locus genotype (MLG). This resulted in a set of 20 clones, with 15 different multi-locus genotypes (Table 1 in SPAAK et al. 2000).

\section{Experimental set-up}

Two large-scale competition experiments were conducted in the Plankton Towers (LAMPERT \& LoOSE 1992) using the 20 clones (4 clones of each taxon) from the Plußsee. The Plankton Towers are dual stainless steel containers of $11.5 \mathrm{~m}$ height and a diameter of $86 \mathrm{~cm}$. The temperature can be adjusted on a $0.5 \mathrm{~m}$ scale. Sampling ports at every $0.5 \mathrm{~m}$ enable precise sampling of the water column. In order to ensure replication, and hence the possibility for statistical analysis, both towers received the same treatment and the effect of different treatments was tested sequentially. The towers were filled with filtered $(10 \mu \mathrm{m})$ water from nearby Lake Schöhsee. We changed food levels during the first experiment from $0.8 \mathrm{mg} \mathrm{C} \mathrm{L}^{-1}$ (high) to $0.3 \mathrm{mg} \mathrm{C} \mathrm{L}^{-1}$ (low). After the first experiment the towers were emptied and cleaned before the second experi- 
ment started. Food levels during the second experiment were $0.8 \mathrm{mg} \mathrm{C} \mathrm{L}^{-1}$. Food levels were established once a day during the high food treatment and twice a day during the low food treatment. Two algal species (Scenedesmus obliquus and Rhodomonas minuta) were used as food in a 9:1 mixture. Both towers had a thermocline $\left(20^{\circ} \mathrm{C} / 8^{\circ} \mathrm{C}\right)$ at a depth of 8 meters. Below the thermocline, an anoxic zone was created to mimic Plußsee conditions. Both experiments were carried out under long day light conditions (16h light, $8 \mathrm{~h}$ dark).

Each tower was stocked with 300 adult daphnids per clone in the first experiment and 200 per clone in the second. The clones were grown in $12 \mathrm{~L}$ containers and acclimated to the experimental temperature, light and food conditions. Samples were usually taken at night, but additional day samples were taken to examine DVM. Sampling was carried out at 10 depths $(0.6,2,3,4,5,6,7,8,9,10$ and 11 meters) in both towers simultaneously using pumps and flow through traps (LAMPERT \& LOOSE 1992). In total, we took 27 night replicated profiles (15 in the first experiment, 12 in the second experiment) and an additional 12 (8 and 4, respectively) day replicated profiles. From each sampling port, 60 randomly chosen adult individuals (if available) were measured and individually frozen at $-80^{\circ} \mathrm{C}$ in microtiter plates for later electrophoretic analysis. We measured body length, and counted the number of eggs in the brood pouch. The rest of each sample was preserved in $4 \%$ formaldehyde and counted to determine total densities. When counting these samples, we distinguished between adults and juveniles. Finally the taxon and clone distribution per sampling date and depth was combined with the formalin counts to calculate the absolute densities for each taxon and clone.

In the first experiment, a fish-factor treatment was established after 37 days in both towers. A $60 \mathrm{~L}$ tank, containing 50 individuals of Leuciscus idus (mean length $6 \mathrm{~cm}$ ), was placed next to each tower. The fish were fed with frozen chironomid larvae. Water was pumped from the towers at a depth of $6 \mathrm{~m}$ into the fish tanks, and then returned to the towers. After 56 days, the first experiment was terminated. During the second experiment water from the fish tanks was added continuously as described above. On day 25 we introduced two fish into each tower, two more fish per tower were added on each of days 32 and 36 . The second experiment was terminated on day 50 .

\section{Data analysis}

The number of individuals of a certain clone at a certain depth was calculated by adding the electrophoretically analysed animals to the formalin counts. These totals (juveniles and adults) were multiplied by the clonal fractions as determined with electrophoresis to calculate the number per litre per clone per depth. Mean night-time density values for the whole tower (adults and juveniles) were used to calculate the instantaneous rate of increase $r$, using the formula for exponential growth:

$$
r=\left[\ln \left(N_{2}\right)-\ln \left(N_{1}\right)\right] /\left(t_{2}-t_{1}\right),
$$

in which $N_{1}$ and $N_{2}$ are the numbers of individuals at sampling time $t_{1}$ and $t_{2}$. Nighttime densities were also used to calculate relative taxon and clonal abundances. 
As a quantitative determination of the overlap in depth distribution of the taxa in the towers we calculated SCHOENER's (1968) index

$$
D_{i j}=1-0.5 \sum_{p=1}^{10}\left|P_{j p}-P_{i p}\right|
$$

in which $P_{i p}$ and $P_{j p}$ are the proportions of taxon $i$ and $\mathrm{j}$, respectively, sampled in port p. $D_{i j}$ varies between 0 and 1 , where 1 is total overlap and 0 is total separation. For each sampling time (in both experiments), we calculated $D$ between all pairs of taxa, and calculated the overall mean $D$ value. Using one-way ANOVA we investigated if treatment (Food-level - fish-factor combinations in experiment 1; the presence of fish experiment 2) significantly affected $D$. For the calculation of $D$, both day and night samples were used since the spatial distribution of clones might change due to DVM.

To calculate genetic diversity, Simpson's index of concentration, (SIMPSON 1949) $\lambda=\Sigma p_{\mathrm{i}}^{2}$, was used, where $p_{\mathrm{i}}$ represents the frequency of the $\mathrm{i}^{\text {th }}$ MLG in the sample. Clonal diversity was calculated as $\mathrm{D}=-\log \lambda$, low values of $\mathrm{D}$ indicate that a single clone is dominant, while high values indicate that many clones are abundant at approximately equal frequencies. D varies between 0 and 1 .

The statistical significance of the introduction of fish on the relative frequencies of the five taxa and the 15 clones was evaluated using Randomized Intervention Analysis (RIA) (Stewart-OAten et al. 1986, CARPenter et al. 1989). In RIA, the absolute value of the average difference (D) between two data series before the fish introduction minus the average difference between the time series after the fish introduction $\left(\left|\bar{D}_{\text {pre }}-\overline{\mathrm{D}}_{\text {post }}\right|\right)$ is an indication of the strength of an experimental effect (observed). We used RIA to compare the first experiment (no fish) with the second where after 25 days fish was introduced. By randomizing the data within both experimental time series and repeatedly re-calculating the absolute value of $\left|\bar{D}_{\text {pre }}-\overline{\mathrm{D}}_{\text {post }}\right|$, we created a frequency distribution of expected values $\left(\overline{\mathrm{D}}_{\text {predicted }}\right)$. The percent area of this curve that falls above $\overline{\mathrm{D}}_{\text {observed }}$ is used as a P-value to test the null hypothesis of no difference between the first experiment without fish introduction and the second with fish. RIA does not detect absolute changes, only relative changes (divergence or convergence) in the experimental time series. We re-calculated $\overline{\mathrm{D}}_{\text {predicted }} 10,000$ times (using Visual Basic macros in Microsoft Excel version 7.0), and used an $\alpha$-value of 0.05 for statistical tests.

The mean size at maturity of the different clones was calculated for both foodlevel and fish-factor treatments (combining data of experiment one and two). Using three-way ANOVAs we tested for significant main effects and interactions. Since $D$. cucullata $\times$ hyalina clones could not be distinguished we could not test for clone effect in this taxon.

\section{Results}

\section{Plußsee}

During our study period, we found large variation in the taxon composition in the Plußsee (Fig. 1). During the last months of 1995, all taxa, except for $D$. hyalina, appeared in roughly equal quantities in the Plußsee. In spring 1996, 


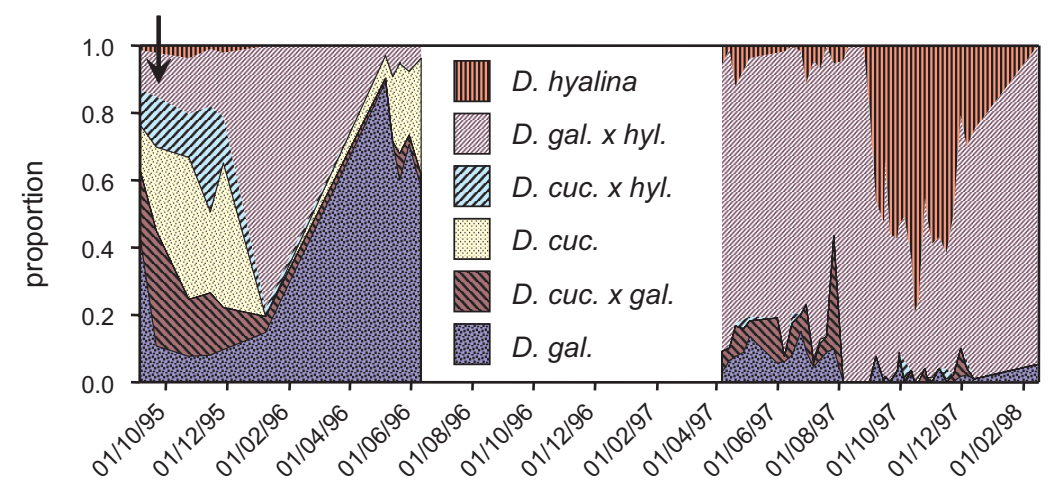

Fig. 1. Relative abundances of the six Daphnia taxa from the D. galeata species complex based on $A A T$ (aspartate aminotransferase) genotypes during the periods Sept. 1995-May 1996 and March 1997-Feb. 1998 in the Plußsee. The latter data are taken from SPAAK et al. (2004). The arrow marks the collection date of the experimental clones.

this pattern was different. D. galeata was the dominant species, representing a maximum of $87 \%$ of the daphnid assemblage in May. Densities of D. cucullata increased during the spring of 1996 and accounted for a maximum of $35 \%$ of the total assemblage at the end of this sampling period on 11 June 1996. D. cucullata $\times$ galeata and D. galeata $\times$ hyalina appeared only at low densities. D. hyalina and D. cucullata $\times$ hyalina were absent in spring 1996 . The pattern was completely different in 1997 . Before the clear water phase in August, with almost no Daphnia in the lake, D. galeata $\times$ hyalina was the dominant taxon constituting 66-91\% of the total daphnid assemblage. D. $g a$ leata and D. cucullata $\times$ galeata occurred at frequencies of $\sim 10 \%$. However after the midsummer decline, relative densities of $D$. hyalina increased up to $79 \%$, the other common taxon was D. galeata $\times$ hyalina. This latter taxon constituted nearly $100 \%$ of the assemblage on 16 February 1998 (Fig. 1).

\section{Tower experiments}

Temporal changes in the relative frequencies of the five Daphnia taxa were similar in both towers. During the first experiment, both towers were dominated by the two largest taxa, D. galeata $\times$ hyalina and $D$. galeata. At the end of experiment one, D. galeata made up $72 \%$ of the population in tower 1 and $40 \%$ in tower 2 . The proportions of D. galeata $\times$ hyalina were $20 \%$ and $40 \%$, respectively (Fig. 2). From the other taxa, only D. cucullata $\times$ galeata could maintain a population, which in tower 1 became constantly smaller. In tower 2 , also some $D$. cucullata $\times$ hyalina could survive until the end of the first experiment. No effect was observed from the changes in treatments (lower food 


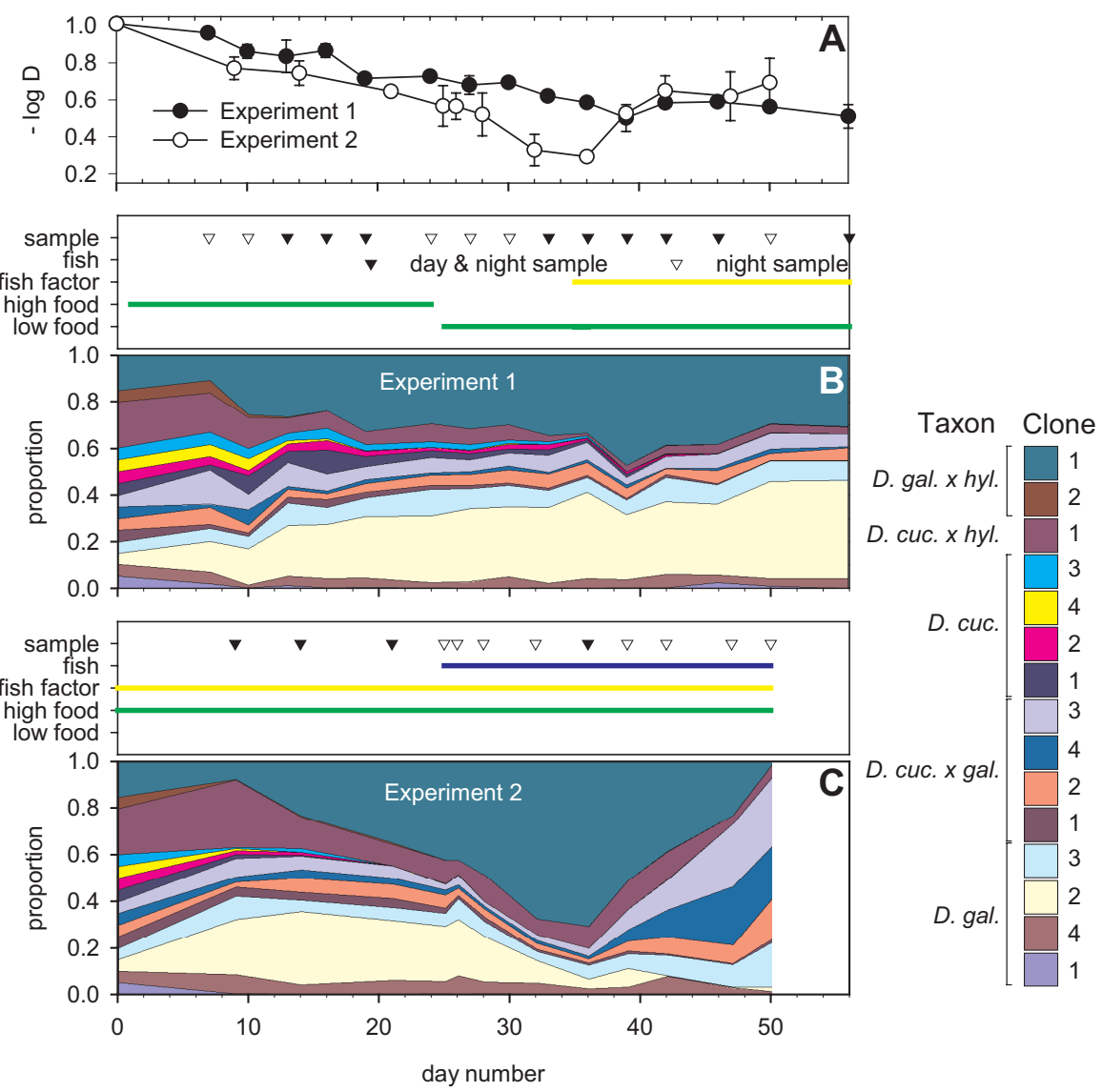

Fig. 2. A. Clonal diversity D, plotted per sampling date for both experiments, calculated as the negative logarithm of Simpson's index of concentration (see text) Mean values of both towers are plotted with standard errors. B. The relative density of the 15 Daphnia clones during the first and second (C) tower experiment (mean of both towers). Because of low amounts of genetic variation in the lake, the D. galeata $\times$ hyalina clone $1\left(\mathrm{GxH}_{-} 1\right)$, actually consist of three clones, D. cucullata $\times$ hyalina clone 1 $\left(\mathrm{CxH}_{-} 1\right)$ is a combination of four clones (see text). The panels above graph $\mathrm{B}$ and $\mathrm{C}$ indicate the experimental setup.

level and addition of fish water). The relative densities of the Daphnia taxa during the first half of the second experiment were very similar to the first experiment for both towers. During the second experiment, D. cucullata became extinct in both towers after 23 days. $P$-values from RIA, comparing the first and second experiment showed a significant effect of the addition of fish for D. galeata and D. cucullata and a marginally significant value for D. cucullata $\times$ galeata $($ Table 1$)$. When fish were added to the towers, $D$. galeata densities 
Table 1. Design of RIA analysis: first part control, in the second part of the experiment the effect of fish is tested on the relative distribution of the Daphnia taxa and clones in the experiment. Bold indicates $P$ values below. Italic $P$ values remain significant after sequential Bonferroni correction.

\begin{tabular}{|c|c|c|c|c|c|c|c|}
\hline \multirow[b]{2}{*}{ Taxon } & \multicolumn{2}{|c|}{$\begin{array}{l}\text { 2nd exp. } \\
\text { No fish }\end{array}$} & \multicolumn{2}{|c|}{ 2nd exp. fish } & \multicolumn{2}{|c|}{ first exp. } & \multirow{2}{*}{$\begin{array}{l}P \\
\text { Significance }\end{array}$} \\
\hline & $\mathrm{n}$ & Avg. D & $\mathrm{n}$ & Avg. D & $\mathrm{n}$ & Avg. D & \\
\hline D. gal & 8 & -0.03 & 14 & 0.26 & 22 & 0.15 & $<0.001$ \\
\hline D. cuc. $\times$ gal. & 8 & 0.01 & 14 & -0.17 & 22 & -0.11 & 0.085 \\
\hline D. cuc. & 8 & 0.10 & 14 & 0.03 & 22 & 0.05 & 0.010 \\
\hline D. cuc. $\times$ hyl. & 8 & -0.07 & 14 & -0.05 & 22 & -0.06 & 0.609 \\
\hline D. gal. $\times$ hyl . & 8 & 0.00 & 14 & -0.06 & 22 & -0.04 & 0.570 \\
\hline \multicolumn{8}{|l|}{ Clone } \\
\hline GaL_1 & 8 & 0.00 & 14 & 0.01 & 22 & 0.00 & 0.540 \\
\hline GaL_2 & 8 & -0.02 & 14 & 0.26 & 22 & 0.16 & $<0.001$ \\
\hline GaL_3 & 8 & 0.02 & 14 & 0.00 & 22 & 0.00 & 0.407 \\
\hline $\mathrm{GaL}_{-} 4$ & 8 & -0.04 & 14 & 0.00 & 22 & -0.01 & 0.032 \\
\hline $\mathrm{CxG}_{-} 1$ & 8 & -0.01 & 14 & 0.00 & 22 & -0.01 & 0.153 \\
\hline CxG_2 & 8 & -0.01 & 14 & -0.02 & 22 & -0.02 & 0.905 \\
\hline CxG_3 & 8 & 0.01 & 14 & -0.06 & 22 & -0.04 & 0.194 \\
\hline CxG_4 & 8 & 0.00 & 14 & -0.08 & 22 & -0.05 & 0.048 \\
\hline Cuc_1 & 8 & 0.05 & 14 & 0.01 & 22 & 0.02 & 0.003 \\
\hline Cuc_2 & 8 & 0.01 & 14 & 0.01 & 22 & 0.01 & 0.429 \\
\hline Cuc_3 & 8 & 0.03 & 14 & 0.01 & 22 & 0.01 & 0.018 \\
\hline Cuc_4 & 8 & 0.01 & 14 & 0.00 & 22 & 0.01 & 0.144 \\
\hline CxH_1 & 8 & -0.07 & 14 & -0.05 & 22 & -0.06 & 0.714 \\
\hline GxH_1 & 8 & 0.00 & 14 & -0.07 & 22 & -0.04 & 0.525 \\
\hline GxH_2 & 8 & 0.00 & 14 & 0.00 & 22 & 0.00 & 0.868 \\
\hline
\end{tabular}

were reduced first, but after day 36 also the relative density of $D$. galeata $\times$ hyalina was reduced in favour of $D$. cucullata $\times$ galeata. Finally, only $D$. cucullata $\times$ galeata $(70 \%)$ and D. galeata $(25 \%)$ were left in both towers (Fig. 2).

At the end of the first experiment, two genotypes dominated both towers, GxH_1 (a combination of three clones) with densities of $22 \%$ and $40 \%$ in tower 1 and 2, respectively, and Gal_2 with relative densities of $54 \%$ and $30 \%$. Three other clones had densities greater than $4 \%$ in both towers (Gal_3, Gal_4, and $\mathrm{CxG} \_2$ ), in tower 1 also clone $\mathrm{CxG}_{-} 3$ and genotype $\mathrm{CxH}_{-} 1$ had final densities above $4 \%$ (Fig. 2). During the second experiment we observed not only a shift in taxa after the introduction of fish, but also a change in clonal composition within taxa. Since only D. galeata and D. cucullata $\times$ galeata remained in both towers, we analyzed the clonal composition during the fish period for these two taxa only. Clone Gal_2, which had been very dominant during the first experiment (Fig. 2) disappeared almost completely when fish were added to the towers. Clone Gal_3 however, with initial densi- 


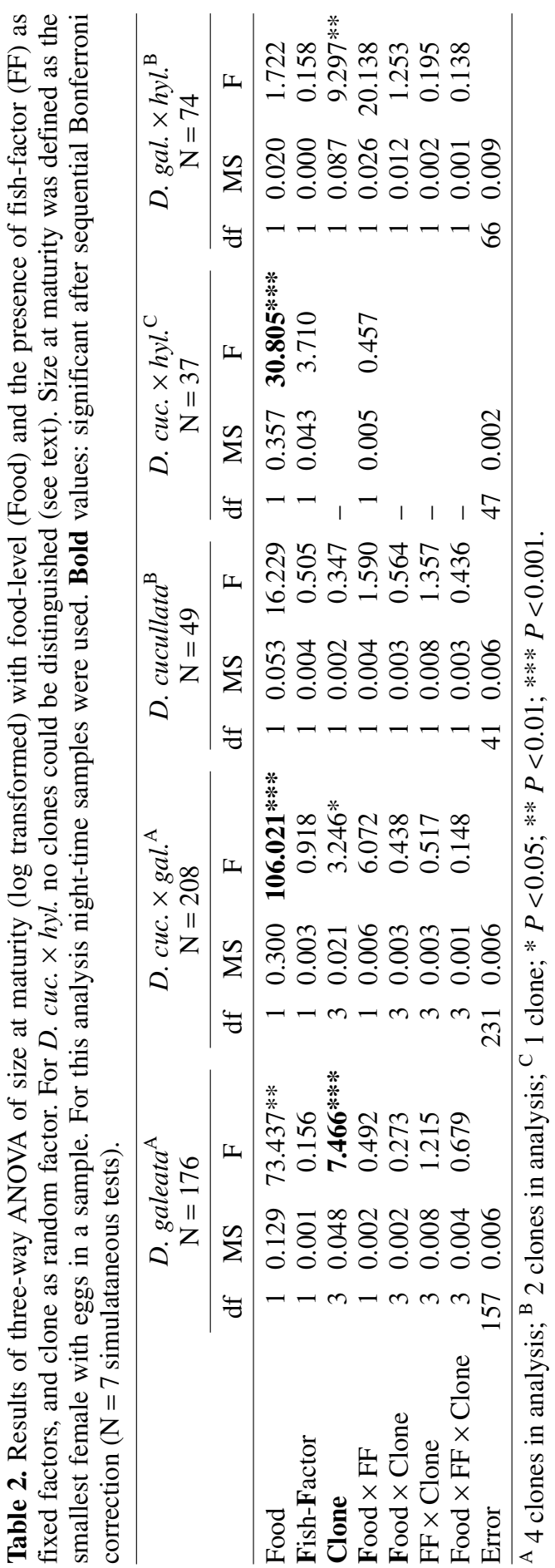


D. galeata
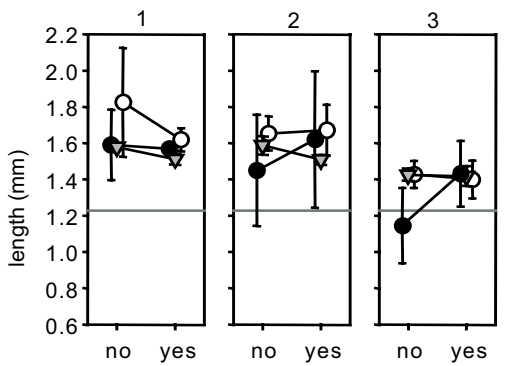

D. cuc. $x$ gal.
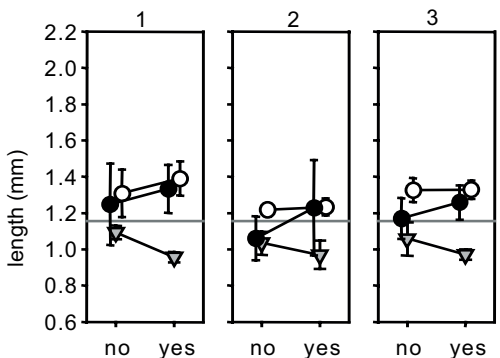
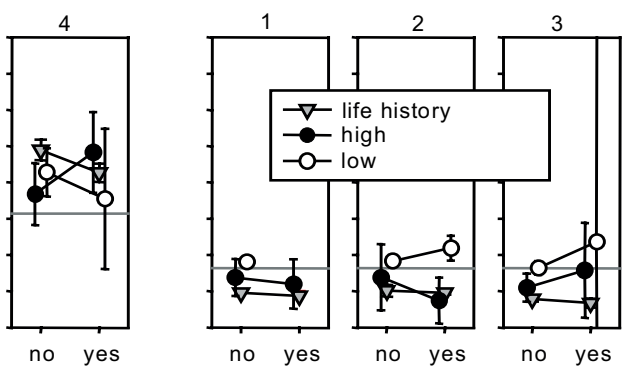

D. cuc. $x$ hyl.
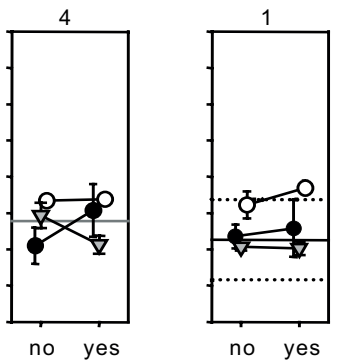

D. cucullata

D. gal. x hyl.
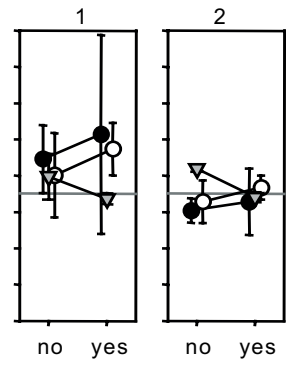

fish factor

Fig. 3. Interaction plots of mean lengths at maturity (with standard errors) against the presence of fish factor for two food levels in the towers. For each Daphnia taxon the reaction of the clones that could be identified are plotted. Because of low densities no data were available for $D$. cucullata clone 4 (Cuc_4). The grey triangles represent the same clones cultured individually under standard conditions (data from SPAAK et al. 2000). For D. cucullata $\times$ hyalina and three clones of $D$. galeata $\times$ hyalina, mean values of the electrophoretically identical clones were calculated. Horizontal lines indicate mean taxon length in the Plußsee on 30 May and 11 June 1996. $95 \%$ confidence limits are within the thickness of the line, except for $D$. cucullata $\times$ hyalina where they are indicated with dotted lines.

ties around 5-10\% in both towers during both experiments took over the $D$. galeata population almost completely (Fig. 2). Within the D. cucullata $\times$ galeata population, the changes were smaller, but clone $\mathrm{CxG}_{-} 4$ doubled its relative density within this taxon. The effect of fish predation on the proportion of Gal_2 and CxG_4 was significant using RIA (Table 1).

Size at maturity, defined as the smallest egg-bearing female present, differed significantly between the taxa (Fig. 3; $\mathrm{F}_{1,434}=4.56 ; \mathrm{P}=0.033$ ) and within $D$. galeata, D. galeata $\times$ hyalina and $D$. cucullata $\times$ galeata between clones (Table 2). The size of the taxa as determined in the Plußsee was in the same range as in the towers, except for D. galeata, which were larger in the towers. When all data were analyzed in a four-way ANOVA with taxon as one of the factors, highly significant food-level and fish-factor effects were found, 

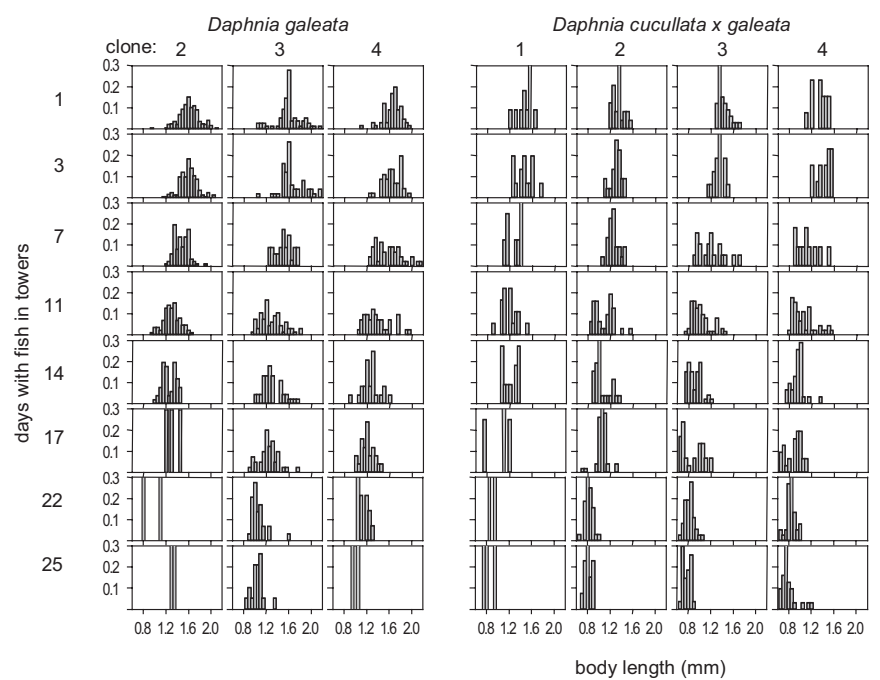

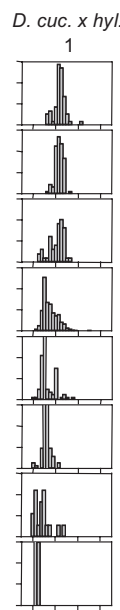

0.8121 .62 .0

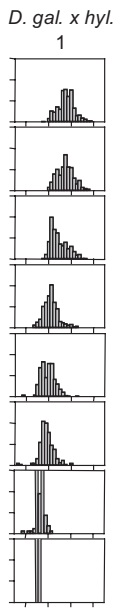

0.81 .21 .62 .0

Fig. 4. Length frequency distributions of 9 clones in the towers during the period that fish were present in the towers. Clones were identified using their electrophoretic genotype.

with higher food levels resulting in smaller animals, while the fish-factor resulted in larger animals (data not shown). In addition, a significant tower effect was found; the animals in tower 1 were always a little larger. There were, however, no significant interactions of other factors with the tower factor, meaning that the animals reacted similarly to the experimental conditions in both towers. We also analyzed the size at maturity of several taxa with threeway ANOVAs with clone as factor. For D. galeata and D. cucullata $\times$ galeata significant clonal effects were found (Table 2), but these separate ANOVAs did not show a significant fish factor effect.

Size at maturity in individual cultures under standardized conditions, as described by SPAAK et al. (2000), were in the same range as the ones found in the tower for all taxa, except for $D$. cucullata $\times$ galeata, which exhibited lower values (Fig. 3). However, the same clones (of the three largest taxa) were significantly smaller under fish kairome conditions (Fig. 3). The mean size of all Daphnia clones in the towers decreased quickly when fish were introduced. Fish preferentially fed upon the larger animals from all clones (Fig. 4). After seven days the size distributions had all shifted towards the left, but larger animals of some clones (e.g. Gal_3, GxH_1) survived the fish predation longer (Fig. 4).

Based on the proportion of the population of a certain taxon at several depths, we calculated Schoener's index $D_{i p}$ and tested in a one way ANOVA (one per experiment) the effect the different treatments (food-level and fish- 


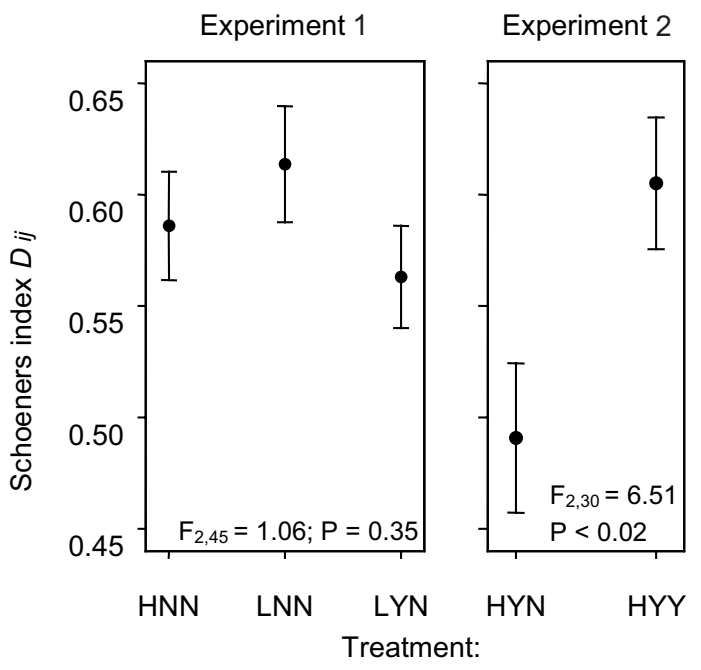

Food: High-Low; Fishfactor: No-Yes; Fish: No-Yes

Fig. 5. Schoener's index $D_{i p}$, calculated as the mean of all possible taxon combinations, based on overlap in depth distributions of the taxa. The treatments during experiment 1 were: High food - No fishfactor - No fish (HNN), Low food and finally fish factor. During the second experiment there was always high food and fish factor but the presence of fish changed.

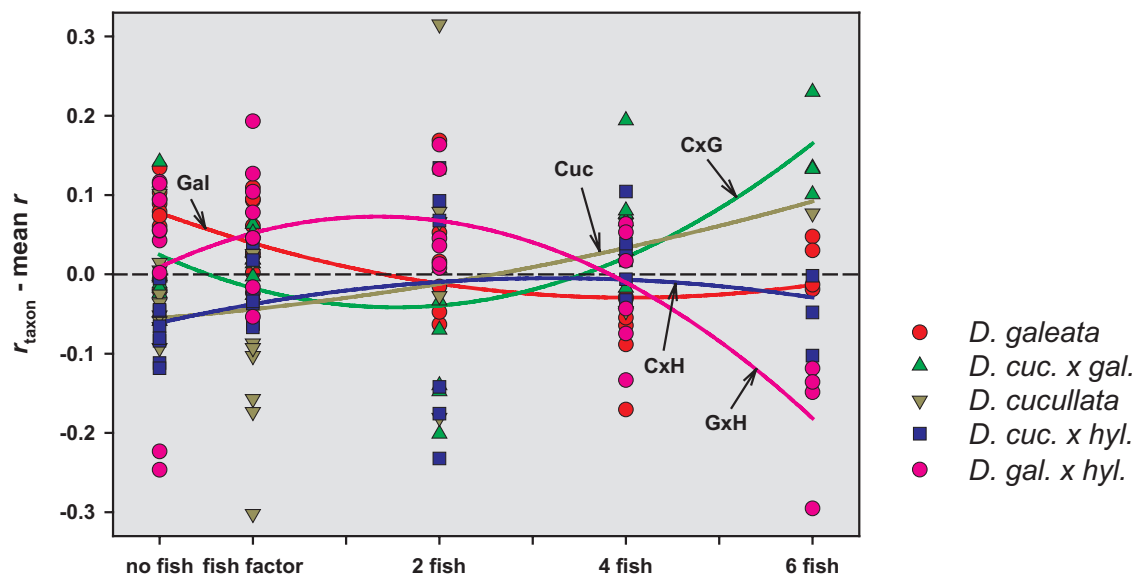

fish predation pressure

Fig. 6. Deviations relative to the mean of the instantaneous rate of increase $r$, smoothed by a three-point running mean, plotted against the fish predation pressure in the towers. Only high food conditions were used. We used the following predation pressure values to fit exponential curves through these data: no fish $=-1$, fish factor $=0$, two fish $=2$, four fish $=4$, and 6 fish $=6 .\left(\mathrm{Gal} \mathrm{r}^{2}=0.34 ; \mathrm{CxG} \mathrm{r}^{2}=0.42 ; \mathrm{Cuc}^{2}=0.10\right.$; $\mathrm{CxH} \mathrm{r}^{2}=0.08 ; \mathrm{GxH} \mathrm{r}^{2}=0.40$ ). 
factor in the first experiment; presence of fish in the second). Only the presence of fish in the second experiment showed a significant effect $\left(F_{2,30}=6.51\right.$, $P<0.02$ ), with higher $D_{i p}$ values under fish conditions (Fig. 5), indicating that in the presence of fish the niche overlap is lower compared to the situation with only fish kairomones in the towers.

As a measure of the success of a given taxon in the towers under different conditions, we used $r_{r}$ (SPAAK \& HoEKSTRA 1997), the deviation of the instantaneous rate of increase of one taxon relative to the grand mean of all taxa. ( $r_{r}=r-\bar{r}, \bar{r}=$ average $r$ for the five taxa on a sampling date), calculated for both towers for the high food period only, since we wanted to concentrate on the direct predation effect. These values were plotted against a measure for fish predation (Fig. 6). When fish were present in the tower, the number of fish was used on the $\mathrm{x}$-axis $(2,4$, and 6 , respectively). No fish in the towers was assigned the value -1 , only fish smell was assigned the value 0 . Through these values exponential curves were fitted giving a relationship between fish predation and the relative success of the Daphnia taxa in the towers. In the beginning (under no fish and fish smell conditions) $r_{r}$ of D. galeata was the highest, then D. galeata $\times$ hyalina had the highest $r_{r}$. With a predation pressure of "4" the fitted curve for $D$. cucullata was the highest, whereas for the highest predation density, the $r_{r}$ of $D$. cucullata $\times$ galeata was the highest. The fitted curve for $D$. cucullata $\times$ hyalina was always below zero, meaning that this taxon was always doing worse than the mean of the others.

\section{Discussion}

Our study is among the first that investigated experimentally the fitness of individual Daphnia clones under semi-natural conditions (but see De MEester et al. 1995). Daphnia has become an important model organism for the study of differences in life-history strategies between taxa and clones within taxa. Furthermore, numerous studies have investigated the role of predator-induced defences in Daphnia, mostly by cultivating individual animals in small containers in media with predator exudates. Although most of these reactions are expected to be adaptive, only predation experiments with Daphnia and the phantom midge larvae Chaoborus have been carried out, showing that Chaoborus induced defences increased the survival rate of Daphnia (LÜNING 1995, REPKA et al. 1995, TOLLRIAN 1995). In the present study we used clones from which the life-history reactions to fish kairomones are known (SPAAK et al. 2000). Since most of the clones had a unique multi-locus (Aat-Pgi-Pgm) genotype, we could compare these life-history results with a clone's migration patterns, body size, and reproductive success, in situations where they had to compete for resources and where they were finally exposed to predation by 
planktivorous fish. Based on the size differences and differences in $r$ between the clones used in our study (SPAAK et al. 2000), we expected that D. galeata and $D$. galeata $\times$ hyalina would be the best competitors in the absence of fish. This was what we found; in both experiments and in both towers, these two taxa dominated (Fig. 2). In the first experiment, D. galeata (the largest taxon) was most abundant, in the second part under high food and fish factor conditions; $D$. galeata $\times$ hyalina did better.

The present study showed that, under different predation levels, different taxa showed the highest relative rate of population increase $r_{r}$ (Fig. 6), indicating that coexistence of these taxa is possible in an environment with changing predation pressure like in Plußsee, the lake from which our clones originated. All parental and hybrid taxa co-occur in this lake, however not permanently but in a dynamical way (Fig. 1). Positive and negative size selective predators (fish, Chaoborus flavicans) present in this lake (Mumm et al. 2000) could be an explanation for this dynamic co-occurrence pattern. Further it is remarkable that the clonal diversity, after an initial reduction, increases during the period of fish predation (Fig. 2 A). Although the number of clones that remain during predation tend to be lower, they were more equally distributed leading to a relatively high clonal diversity. The main question that needs to be answered is: which traits played the dominant role in the determination of taxon success? The study of SPAAK et al. (2000) suggested that changes in life-history traits under conditions with kairomones alone were enough to explain shifts in dominance of different taxa. They showed that, especially the larger taxa (D. galeata, D. galeata $\times$ hyalina, and D. cucullata $\times$ galeata $)$ reduced their size at maturity under the influence of fish kairomones, whereas the smaller taxa $(D$. cucullata and D. cucullata $\times$ hyalina) did not show a significant reaction. Based on these data, SpaAK et al. (2000) modelled the influence of size-selective predation on the intrinsic rate of increase of the different taxa. They showed that with changing predation regimes, the five taxa might co-occur.

We hypothesized that the reduction in size at maturity (SAM) in the presence of fish factor, as found under laboratory conditions (SPAAK et al. 2000), would also occur in the towers. In our study we could determine size at maturity of individual clones under different conditions. We defined size at maturity as the smallest animal of a given clone that was observed with eggs. This method is of course less accurate compared to life-history experiments where individual animals can be followed. Our method is considered to be an underestimation (STIBOR \& LAMPERT 1993). When the tower observations are compared with the individual life-history data (Fig. 3), one can see that size at maturity in the towers was similar to those determined in the life-history experiment. Only the $D$. cucullata $\times$ galeata clones tended to reproduce at a smaller size than in the life-history experiment. However, in the towers, no decrease in size at maturity could be observed under fish factor conditions (Fig. 3, Table 
2). A possible explanation for this discrepancy could be the variable food conditions in the towers. Although we established the food conditions every day (or twice a day during the low food treatment), Daphnia densities were so high that the food was consumed very rapidly, after which food was limiting again. Therefore, our initial plan to investigate how food condition influences the ability of the different taxa to react to fish could not be realized. The mean size of the daphnids in the towers decreased during the period of fish predation (data not shown), which demonstrates that the fish ate the larger daphnids first (Fig. 4). It is interesting, however, that some taxa became relatively smaller than others. D. galeata, for example, was no longer larger than D. galeata $\times$ hyalina at the end of the experiment, and D. cucullata $\times$ galeata became smaller than $D$. cucullata $\times$ hyalina. This stronger reduction in size might provide an additional explanation as to why these two taxa became the most abundant by the end of the experiment.

In the present study, $D$. cucullata $\times$ galeata became the dominant taxon in both towers after 20 days of fish predation (Fig. 2). Specifically CxG_03 and CxG_04 were doing well. In addition, one D. galeata clone was present at a relatively high density at the end of the experiment (Fig. 2). Of interest is, whether the individual life history characters of these clones could predict their success. Gal_03 was the smallest D. galeata clone in the experiment, but still larger than all $D$. galeata $\times$ hyalina clones, it also showed no significant reduction of SAM under fish factor conditions. CxG_03 and CxG_04 were not smaller then the other $D$. cucullata $\times$ galeata clones in this experiment and did not show a stronger reaction to fish factor in other life-history traits (SPAAK et al. 2000). Therefore, behavioural characters of these clones might explain their competitive success. In fact, Gal_03 was the only D. galeata clone that migrated in the presence of fish, thus explaining its success (data not shown). These results confirm the findings of De MeEster et al. (1995) who, in a competition experiment with three D. galeata $\times$ hyalina clones in the plankton towers, found that the clones from which the larger individuals migrated to larger depths during the night were the best competitors. The success of the D. cucullata $\times$ galeata clones can be explained by their relative small size compared to the other taxa in combination with high growth rates. The other larger clones were consumed first by the positive-size-selective fish predators; this resulted in an increase in the relative abundance of the D. cucullata $\times$ galeata hybrids (Figs 2,4).

Several studies have shown that predation is a major factor determining the outcome of competition between different Daphnia species (COOPER \& SMITH 1982, Bengtsson 1986, Milbrink \& Bengtsson 1991). As was shown before, predation by positively size selective fish seems also an important factor for creating a variable environment where Daphnia hybrids can co-exist with their parental species (SPAAK \& HoEKSTRA 1995, 1997). However, prior to this 
present study, little was known about how predator-induced life-history and behavioural changes influence the competitive relationships between Daphnia hybrids and their parental species, although De MeEster et al. (1995) showed that coexistence of hybrid clones of $D$. galeata $\times$ hyalina could be maintained by alternative anti-predator mechanisms (i.e. vertical migration, shifts in lifehistories). The present study is one of the first to show experimentally that the presence of a predator increases the possibilities for co-occurrence of taxa and clones in a Daphnia hybrid species complex. The presence of fish smell significantly decreased Schoener's index $D$, a measure of spatial niche overlap of the different taxa (Fig. 5). This reduction was however only observed in the second experiment. There can be several reasons for this reduction in niche overlap. Most likely, the increased DVM behaviour of certain taxa can lead to differential distributions of the animals throughout the water column. Because of this increased spatial separation, the taxa should have a lower frequency of interactions, and compete less for the resources available at the different depths. The larger taxa showed an increase in vertical migration, with fish kairomones present. Normally, feeding conditions are worse deeper in the lake, which implies that the relative fitness of the larger taxa will decline because of the migration. Hence, the competitive exclusion process will be slower. The fact that $D$ increased again when fish was present seems not logic. It might however be an artefact of the experimental conditions. The fish ate away several taxa completely and reduced densities dramatically in the towers. This might have led to higher $D$ values as theoretically expected.

Our data also show that body size was a very important trait for Daphnia determining their survival rate in the presence of fish. The reduction in body size, as observed in the study by SpaAK et al. (2000), was not observed in the current experiment in the towers (see also von ElerT \& STIBOR 2006). In the towers, the behavioural reaction to fish kairomones seemed to be more important than life-history changes. Does this mean that life-history reactions to fish kairomones have no effect in the field? The predation pressure in our experiments was artificially high, probably $\sim 8$ to $\sim 24$ times higher than in the Pluß-

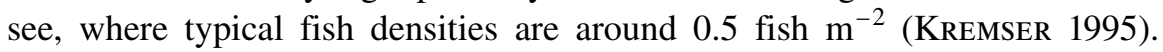
These high predation pressures enabled us to demonstrate the advantage of smaller taxa compared to larger taxa and the advantage of migration behaviour. Obviously, lower predation levels are needed to be able to assess the advantage of predator-induced changes in life-histories.

\section{Acknowledgments}

During the experimental phase of this study PS and MB were supported by MaxPlanck-Society fellowships. We thank WINFRIED LAMPERT who brought us to Plön and always supported our work. This study would have been impossible without the op- 
timal research conditions created by him in Plön. We also thank ANGelika Denk, Gregor Fussmann, Birgit Klein, Eva Momberger-Geissler, Larry Weider and Gerhard Augustin for their help during the experimental phase of this project. We especially thank CHARLES W. RAMCHARAN for providing the Excel macro to calculate the RIA. We thank KirSten KesSLER and LARRY WeIDER fore their comments on an earlier version of this manuscript.

\section{References}

Anderson, E. (1953): Introgressive hybridization. - Biol. Rev. Camb. Philos. Soc. 28: $280-307$.

Anderson, E. \& StebBins, G. L. (1954): Hybridization as an evolutionary stimulus. Evolution 8: $378-388$.

ARNOLD, M. L. (1997): Natural hybridization and evolution. - Oxford University Press, Oxford UK. 215 pp.

Barton, N. H. \& HewitT, G. M. (1985): Analysis of hybrid zones. - Annu. Rev. Ecol. Syst. 16: $113-148$.

BenGTSSON, J. (1986): Life histories and interspecific competition between three Daphnia species in rockpools. - J. Anim. Ecol. 55: 641-655.

BERT, T. M. \& ARNOLD, W. S. (1995): An empirical test of predictions of two competing models for the maintenance and fate of hybrid zones: Both models are supported in a hard-clam hybrid zone. - Evolution 49: 276-289.

Boersma, M., Spaak, P. \& De Meester, L. (1998): Predator-mediated plasticity in morphology, life history, and behavior of Daphnia: The uncoupling of responses. - Amer. Nat. 152: 237-248.

Boersma, M. \& ViJverberg, J. (1994): Seasonal variations in the condition of two Daphnia species and their hybrid in a eutrophic lake: Evidence for food limitation. - J. Plankton Res. 16: 1793-1809.

BRooks, J. L. \& Dodson, S. I. (1965): Predation, body size, and composition of plankton. - Science 150: $28-35$.

Bullini, L. (1985): Speciation by hybridization in animals. - Boll. Zool. 52: 121-137.

Carpenter, S. R., Frost, T. M., Heisey, D. \& Kratz, T. K. (1989): Randomized intervention analysis and the interpretation of whole-ecosystem experiments. - Ecology 70: $1142-1152$.

Cooper, S. D. \& SMITH, D. W. (1982): Competition, predation and the relative abundances of two species of Daphnia. - J. Plankton Res. 4: 859-879.

Cracraft, J. (1989): Speciation and its ontology: the empirical consequences of alternative species concepts for understanding patterns and processes of differentiation. - In: Otte, D. \& Endler, J. A. (eds): Speciation and its consequences. - Sinauer Associates, Inc., Sunderland, Massachusetts. pp. 28-59.

Crease, T. J., Lee, S. K., Yu, S. L., Spitze, K., Lehman, N. \& Lynch, M. (1997): Allozyme and mtDNA variation in populations of the Daphnia pulex complex from both sides of the Rocky Mountains. - Heredity 3: 242-251.

DARWIN, C. (1859): On the origin of species by means of natural selection, or the preservation of favoured races in the struggle for life. - John Murray, London. 502 pp. 
De Meester, L., Weider, L. J. \& Tollrian, R. (1995): Alternative anti-predator defences and genetic polymorphism in a pelagic predator-prey system. - Nature 378: $483-485$.

GliwiCZ, Z. M. \& LAMPERT, W. (1990): Food thresholds in Daphnia species in the absence and presence of blue-green filaments. - Ecology 71: 691-702.

Grant, P. R. (1993): Hybridization of Darwin finches on Isla Daphne Major, Galápagos. - Phil. Trans. R. Soc. Lond. B 340: 127-139.

Grant, P. R. \& Grant, B. R. (2002): Unpredictable Evolution in a 30-Year Study of Darwin's Finches. - Science 296: 707-711.

Hann, B. J. \& Hebert, P. D. N. (1982): Re-interpretation of genetic variation in Simocephalus (Cladocera, Daphniidae). - Genetics 102: 101-107.

Hebert, P. D. N. \& Beaton, M. J. (1989): Methodologies for allozyme analysis using cellulose acetate electrophoresis. - Helena laboratories Beaumont, Texas. $32 \mathrm{p}$.

Hennig, W. (1966): Phylogenetic Systematics. - University of Illinois Press, Urbana. $280 \mathrm{pp}$.

Krambeck, H., Albrecht, D., Hickel, B., Hofmann, W. \& Arzbach, H. (1994): Limnology of the Plußsee. - In: Overbeck, J. \& Chróst, R. (eds): Microbial Ecology of Lake Plußsee. - Springer, New York, Berlin. pp. 1-23.

Kremser, A. (1995): Nahrungskettenmanipulation im Plußsee: Die Regulation der planktivoren Fische (Perca fluviatilis L. und Rutilis rurilis) durch Ressourcen und Konsumenten. - PhD Thesis, Christian-Albrecht-Universität, Kiel, Germany 121 pp.

LAmpert, W. \& Loose, C. J. (1992): Plankton Towers - bridging the gap between laboratory and field experiments. - Arch. Hydrobiol. 126: 53-66.

Lass, S. \& SpaAK, P. (2003): Chemically induced anti-predator defences in plankton: a review. - Hydrobiologia 491: 221-239.

Lehman, N., Eisenhawer, A., Hansen, K., Mech, L. D., Peterson, R. O., Gogan, P. J. P. \& WAYNE, R. K. (1991): Introgression of coyote mitochondrial DNA into sympatric North American gray wolf populations. - Evolution 45: 104-119.

LiEDER, U. (1987): The possible origin of Daphnia cucullata procurva Poppe 1887 in the lakes of the Pomeranian Lakeland by hybridization in the past. - Hydrobiologia 145: 201-211.

LÜNING, J. (1995): How do predator-induced changes affect prey vulnerability? Larvae of Chaoborus flavicans (Diptera: Chaoboridae) feeding on Daphnia pulex (Crustacea: Cladocera). - Freshwat. Biol. 34: 523-530.

MAYr, E. (1942): Systematics and the origin of species. - Columbia University Press, New York. 332 pp.

- (1963): Animal species and evolution. - Belknap Press of Harvard University Press, Cambridge, Massachusetts. 797 pp.

Milbrink, G. \& Bengtsson, J. (1991): The impact of size-selective predation on competition between two Daphnia-species - a laboratory study. - J. Anim. Ecol. 60: 1009-1028.

Moore, W. S. (1977): An evaluation of narrow hybrid zones in vertebrates. - Q. Rev. Biol. 52: 263-277.

MoORE, W. S. \& KoENIG, W. D. (1986): Comparative reproductive success of yellowshafted, red-shafted and hybrid flickers across a hybrid zone. - Auk 103: 42-51. 
Mumm, H., Kremser, A. \& Lampert, W. (2000): Zooplankton of a small eutrophic lake: impact of a biomanipulation attempt. - Arch. Hydrobiol. Beih. Ergebn. Limnol. 55: 205-226.

Overbeck, J. \& Chróst, R. (eds) (1994): Microbial Ecology of Lake Plußsee. - Ecol. Stud. 105, Springer, New York, Berlin, 392 pp.

Pijanowska, J., Dawidowicz, P., Howe, A. \& Weider, L. J. (2006): Predator-induced shifts in Daphnia life-histories under different food regimes. - Arch. Hydrobiol. 167: $37-54$, this issue.

RepKa, S., Walls, M. \& Ketola, M. (1995): Neck spine protects Daphnia pulex from predation by Chaoborus, but individuals with longer tail spine are at a greater risk. - J. Plankton Res. 17: 393-403.

SchoENER, T. W. (1968): The Anolis lizards of Bimini: resource partitioning in a complex fauna. - Ecology 49: 704-726.

SchWENK, K. \& SPAAK, P. (1995): Evolutionary and ecological consequences of interspecific hybridization in cladocerans. - Experientia 51: 465-481.

- - (1997): Ecological and genetics of interspecific hybridization in Daphnia. - In: Streit, B., StÄDler, T. \& Lively, C. M. (eds): Evolutionary ecology of freshwater animals. - Birkhäuser Verlag, Basel. pp. 199-229.

SCRIBNER, K. T. (1993): Hybrid zone dynamics are influenced by genotype-specific variation in life-history traits - experimental evidence from hybridizing Gambusia species. - Evolution 47: 632-646.

Seehausen, O. (2004): Hybridization and adaptive radiation. - Trends Ecol. Evol. 19: $198-207$.

Shan, R. K. \& Frey, D. G. (1983): Pleuroxus denticulatus and P. procurvus (Crustacea: Chydoridae) in North America: distribution, experimental hybridization and the possibility of natural hybridization. - Can. J. Zool. 61: 1605-1617.

Simpson, E. H. (1949): Measurement of diversity. - Nature 163: 688.

SPAAK, P. (1995): Sexual reproduction in Daphnia: interspecific differences in a hybrid species complex. - Oecologia 104: 501-507.

- (1996): Temporal changes in the genetic structure of the Daphnia species complex in Tjeukemeer, with evidence for backcrossing. - Heredity 76: 539-548.

Spank, P., Denk, A., Boersma, M. \& Weider, L. J. (2004): Spatial and temporal patterns of sexual reproduction in a hybrid Daphnia species complex. - J. Plankton Res. 26: 625-635.

SPAAK, P. \& HOEKSTRA, J. R. (1995): Life history variation and the coexistence of a Daphnia hybrid with its parental species. - Ecology 76: 553-564.

- - (1997): Fish predation on a Daphnia hybrid species complex: A factor explaining species coexistence? - Limnol. Oceanogr. 42: 753-762.

Spate, P., Vanoverbeke, J. \& Boersma, M. (2000): Predator induced life history changes and the coexistence of five taxa in a Daphnia species complex. - Oikos 89: $164-174$.

StaCE, C. A. (1987): Hybridization and the plant species. - In: Krystyna, M. \& URBANSKA, K. M. (eds): Differentiation patterns in higher plants. - Academic Press, London. pp. 115-127.

Stewart-Oaten, A., Murdoch, W. W. \& Parker, K. R. (1986): EnvironmentalImpact Assessment - Pseudoreplication in Time. - Ecology 67: 929-940.

STIBOR, H. \& LAMPERT, W. (1993): Estimating the size at maturity in field populations of Daphnia (cladocera). - Freshwat. Biol. 30: 433-438. 
Stich, H. B. \& LAmpert, W. (1981): Predator evasion as an explanation of diurnal vertical migration by zooplankton. - Nature 293: 396-398.

Tollrian, R. (1995): Chaoborus crystallinus predation on Daphnia pulex: Can induced morphological changes balance effects of body size on vulnerability? - Oecologia 101: 151-155.

VANNI, M. J. (1986): Competition in zooplankton communities: suppression of small species by Daphnia pulex. - Limnol. Oceanogr. 31: 1039-1056.

ViJverberg, J., DoKsÆTer, A. \& van DonK, E. (2006): Contrasting life history responses to fish released infochemicals of two co-occurring Daphnia species that show different migration behaviour. - Arch. Hydrobiol. 167: 89-100, this issue.

Von Elert, E. \& Stibor, H. (2006): Predator-mediated life history shifts in Daphnia: enrichment and preliminary chemical characterisation of a kairomone exuded by fish. - Arch. Hydrobiol. 167: 21-35, this issue.

Weider, L. J., HOBæK, A., CreASe, T. J. \& Stibor, H. (1996): Molecular characterization of clonal population structure and biogeography of arctic apomictic Daphnia from Greenland and Iceland. - Mol. Ecol. 5: 107-118.

Weider, L. J. \& Stich, H. B. (1992): Spatial and temporal heterogeneity of Daphnia in Lake Constance; intra- and interspecific comparisons. - Limnol. Oceanogr. 37: $1327-1334$.

Whitham, T. G., Morrow, P. A. \& Potts, B. M. (1991): Conservation of hybrid plants. - Science 254: 779-780.

Wolf, H. G. \& MoRT, M. A. (1986): Interspecific hybridization underlies phenotypic variability in Daphnia populations. - Oecologia 68: 507-511.

Submitted: 15 January 2006; accepted: 15 April 2006. 